\title{
Research on the Relationship between Foreign Trade and Carbon Emissions based on Econometric Model
}

\author{
Jian-Na ZHAO ${ }^{1, a}$, Xiao-Chen SHAN ${ }^{1, b,{ }^{*}}$, Lei FENG ${ }^{1, c}$ \\ ${ }^{1}$ North China Electric power University, Hebei Baoding 071003, China \\ azhjnzhf@163.com, ${ }^{b}$ jjsxc1022@163.com, ${ }^{c}$ fenglei0011@126.com \\ ${ }^{*}$ Corresponding author
}

Key words: Econometric, Foreign trade, Carbon emission

\begin{abstract}
Based on the data of foreign trade import and export volume and carbon emissions in China from1990 to 2012, statistical analysis through econometric models, the results showed that both showed a significant linear correlation. By stationary test and co-integration explain the existence of long-term stable equilibrium relationship between carbon emissions and foreign trade, through error correction shows the short-term dynamic relationship between them, the results show that the development of foreign trade will continue affect our environment. Finally, we put forward a proposal of industrial development.

As economic of China strength, our influence in the world also greater and greater. According to customs statistics, 2012 foreign trade volume of China reached \$3866.76 billion, more than the United States ranks first in the world. On the surface, China has obtained the aura of world trade, but follow the harvest is big business environmental issues, in particular pollution problems. According to the British Tyndall Centre for Climate Change Research "Global Carbon Project" research in 2012 shows that, in 2011, the first three countries in global carbon emissions were China (28\%), the U.S. (16\%), EU (11\%)[1], as can be seen from the data, our carbon emissions have exceeded the sum of the U.S. and the EU. So the analysis of the relationship between carbon emissions and our foreign trade, have particularly important practical significance for the sustainable development of trade and ecological terms.
\end{abstract}

\section{Analysis of the data and relationships ${ }^{1}$}

\section{Calculation of carbon emissions}

Since in the China Statistical Yearbook, did not give the corresponding carbon emissions statistics, so we need to find a formula of carbon emissions over the years. The main source of carbon emissions is the fossil fuel, fossil fuel energy including coal, oil and natural gas three categories. So for the calculation of carbon emissions, Academia use the consumption of various types of energy multiplied by the carbon emission factor of various types energy, and then add the sum total[2].This article uses a formula for estimating carbon emissions from Xu Guoquan[3] and other scholars. The formula is:

$$
C=\sum_{i} m_{i} \alpha_{i}
$$

\footnotetext{
${ }^{1}$ Philosophy and Social Science Research Base of Hebei Province
} 
In the formula, $\mathrm{C}$ representative of carbon emissions, $\mathrm{m}_{\mathrm{i}}$ is the consumption standard amount of energy $i$, that is in accordance with the standard coal reference coefficient converted to unified thermal units of energy - standard coal, $\alpha i$ is the carbon emission factor of energy i. Due to the current statistics on carbon emission factor have no consistent conclusion, to avoid large errors, carbon emission factor used in this article is the average calculated according to each Energy Agency of Table 1, then according to the formula and energy consumption from Energy Statistics Yearbook of China and composition data, finishing derived by calculating the carbon emissions data of 1990-2012 years. Table 2 shows the annual carbon emissions by 1990-2012 and a summary of import and export value of China.

Tab. 1 The carbon emission factors of each kinds of energy

\begin{tabular}{cccc}
\hline Data Sources & \multicolumn{3}{c}{ carbon emission factors } \\
& Coal & Petroleum & Natural gas \\
U.S. Department of Energy & 0.702 & 0.478 & 0.389 \\
DOE/EIA & & & \\
IPCC & 0.755 & 0.585 & 0.448 \\
National CST of climate change project & 0.726 & 0.583 & 0.409 \\
NDRC Energy Research Institute & 0.748 & 0.583 & 0.444 \\
Average & 0.733 & 0.557 & 0.423 \\
\hline
\end{tabular}

Tab. 2 Chinese carbon emissions and import and export of foreign trade in 1990-2012

\begin{tabular}{|c|c|c|c|c|c|}
\hline \multirow[t]{3}{*}{ Years } & $\begin{array}{c}\text { Carbon } \\
\text { emissions }\end{array}$ & $\begin{array}{l}\text { Import and } \\
\text { export volume }\end{array}$ & Years & $\begin{array}{c}\text { Carbon } \\
\text { emissions }\end{array}$ & $\begin{array}{l}\text { Import and } \\
\text { export volume }\end{array}$ \\
\hline & C/One hundred & $\mathrm{X} /$ & & C/One hundred & X/ \\
\hline & $\begin{array}{l}\text { million } \\
\text { Tons }\end{array}$ & $\begin{array}{l}\text { One trillion } \\
\text { dollars }\end{array}$ & & $\begin{array}{c}\text { million } \\
\text { Tons }\end{array}$ & $\begin{array}{l}\text { One trillion } \\
\text { dollars }\end{array}$ \\
\hline 1990 & 6.5133 & 0.11544 & 2002 & 10.0888 & 0.62077 \\
\hline 1991 & 6.8655 & 0.13570 & 2003 & 11.7680 & 0.85099 \\
\hline 1992 & 7.2095 & 0.16553 & 2004 & 13.6324 & 1.15455 \\
\hline 1993 & 7.6203 & 0.19570 & 2005 & 15.1097 & 1.42191 \\
\hline 1994 & 8.0357 & 0.23662 & 2006 & 16.5793 & 1.76044 \\
\hline 1995 & 8.5515 & 0.28086 & 2007 & 17.9480 & 2.17657 \\
\hline 1996 & 8.7946 & 0.28988 & 2008 & 18.4452 & 2.56326 \\
\hline 1997 & 8.7607 & 0.32516 & 2009 & 19.3872 & 2.20754 \\
\hline 1998 & 8.7589 & 0.32395 & 2010 & 20.2399 & 2.97400 \\
\hline 1999 & 9.0767 & 0.36063 & 2011 & 21.7892 & 3.64186 \\
\hline 2000 & 9.3168 & 0.47429 & 2012 & 22.5269 & 3.86676 \\
\hline 2001 & 9.5089 & 0.50965 & & & \\
\hline
\end{tabular}

\section{Data Analysis}

According to table 2,make carbon emissions and import and export volume plotted by years, that got both trends(Figure 1).In 23 years time, our foreign trade import and export volume grew by 33.5 times, Especially since the beginning of 2000, its growth rate significantly increased, In addition to 2009 due to the financial crisis, other years, there is an increasing trend basically, also, 
from Figure 1, carbon emissions and the import and export trend,we can see that, growth trend of our carbon emissions compared with the growth trend of import and export trade, maintaining a substantially similar growth trend. So, there is a certain degree of linear relationship between carbon emissions and our country's foreign trade.

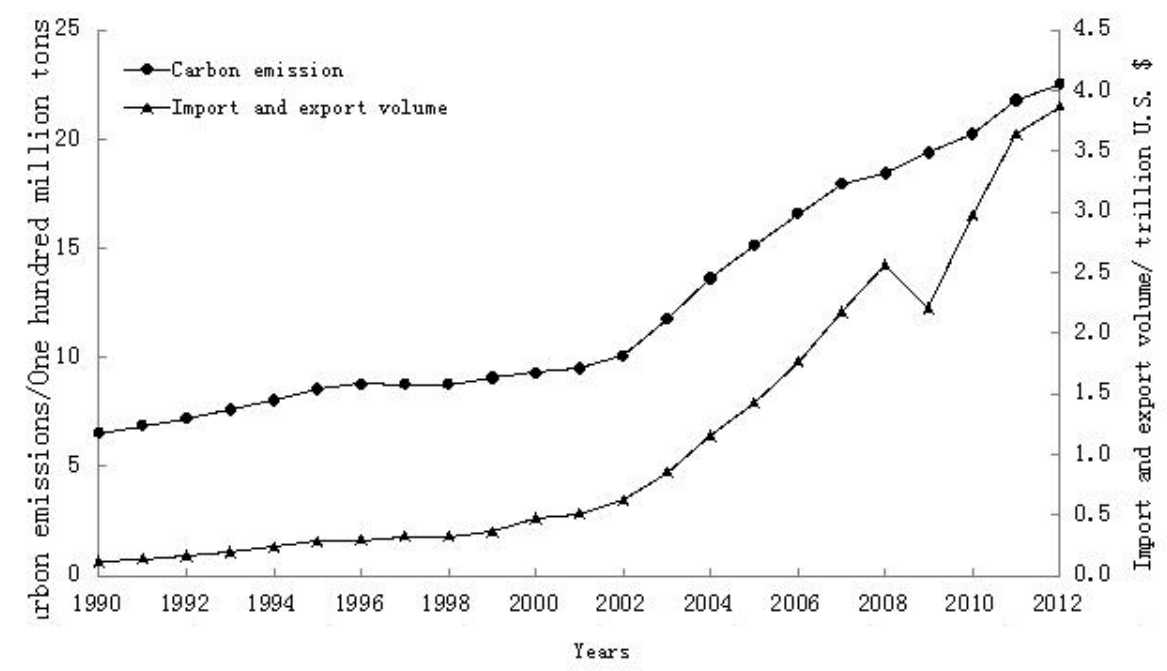

Fig 1 The trend of carbon emission and foreign trade

\section{Correlation Analysis}

After calculated by Eviews6.0 on carbon emissions and time series data of import and export trade volume, obtained the linear equations between the two: LNC $=0.3603 \times \mathrm{LNX}+8.4717$, correlation coefficient $\mathrm{R}=0.9942$,statistics $\mathrm{F}=1360$, the probability value corresponding with statistics $F p \approx 0$, less than significant level $\alpha=0.05$, therefore reject the irrelevant hypothesis $\mathrm{H} 0$, illustrate a highly positive correlation between foreign trade of China and carbon emissions.

Even after calculated by Eviews6.0, carbon emissions and import and export trade show highly significant relationship, But the upward trend of growing together on the table between the two may also appear spurious regression phenomenon. To avoid the spurious regression phenomenon arise between carbon emissions and foreign trade turnover, correlation test analysis needs to be.

\section{Analysis}

\section{Unit Root Tests}

For stationary of time series in addition to graphics and intuitive judgment, but also can be tested using statistics. Compared to graphics judge, the statistical test would be more accurate, but also more important. Unit root test is a test method commonly applied in statistical tests. There are a variety of unit root test methods, we use $\mathrm{ADF}[4]$ in this article.

As the number of samples used in this paper is only 23 , in order to avoid a reduction in the degree of freedom, number of lags in the test equation is not suitable for too much, therefore, this paper selects fewer lags. Using software Eviews6.0,we carry on the relevant time series data between carbon emissions $\mathrm{C}$ and import and export volume $\mathrm{X}$ with unit root test, test results are shown in Table 3. 
Tab. 3 The ADF unit root tests on carbon emission and foreign trade

\begin{tabular}{|c|c|c|c|c|c|c|c|}
\hline \multirow[t]{2}{*}{ Sequence } & \multicolumn{7}{|c|}{ Level } \\
\hline & $\begin{array}{l}\text { Inspection } \\
\text { forms } \\
(\mathrm{c}, \mathrm{t}, \mathrm{n})\end{array}$ & $\mathrm{ADF}$ & $\begin{array}{c}1 \% \\
\text { thresholds }\end{array}$ & $\begin{array}{c}5 \% \\
\text { threshold } \\
\mathrm{s}\end{array}$ & $\begin{array}{l}10 \% \\
\text { thresholds }\end{array}$ & $\begin{array}{l}\text { Accompani } \\
\text { ed } \\
\text { probability }\end{array}$ & Conclusion \\
\hline $\mathrm{LNC}$ & $(c, t, 1)$ & -2.590761 & -4.467895 & -3.644963 & -3.261452 & 0.2872 & Not smooth \\
\hline $\mathrm{LN} X$ & $(c, t, 1)$ & -1.780595 & -4.467895 & -3.644963 & -3.261452 & 0.6776 & Not smooth \\
\hline$\triangle \mathrm{LNC}$ & $(c, t, 1)$ & -2.176263 & -4.498307 & -3.658446 & -3.268973 & 0.4761 & Not smooth \\
\hline$\Delta \mathrm{LN} X$ & $(c, t, 1)$ & -3.071752 & -4.498307 & -3.658446 & -3.268973 & 0.1391 & Not smooth \\
\hline$\Delta^{2} \mathrm{LNC}$ & $(c, t, 1)$ & -3.301268 & -4.532598 & -3.673616 & -3.277364 & 0.0961 & Smooth \\
\hline$\Delta^{2} \mathrm{LN} X$ & $(c, t, 1)$ & -5.621345 & -4.532598 & -3.673616 & -3.277364 & 0.0012 & Smooth \\
\hline
\end{tabular}

After the unit root test results on carbon emissions and import and export trade volume, as can be seen. When their time series have been the second-order differential can become stationary sequence, thus, their original sequences are both the single whole sequence of order 2. we can prove that, there may exist long-term stable relationship between the two, Then need to analyze with co-integration test.

\section{Co - integration test}

Since carbon emissions and import and export volume are both second-order single whole, we can use co-integration test. This article use Engle-Granger two-step method to make co-integration test .The first step is to estimate the long-run equilibrium equation of carbon emissions and the import and export volume by OLS method: $\mathrm{LNCt}=0.3603 \times \mathrm{LNXt}+8.4717$. Then calculated corresponding residuals according to the equation.et $=\mathrm{LNCt}-0.3603 \times \mathrm{LNXt}-8.4717$; The second step is to test the stationary of residuals et.if the residual series items et is stationary, so the relationship between the variables $\mathrm{Yt}$ and $\mathrm{Xt}$ is co-integration. Otherwise, there is no co-integration. Residuals stationary test results are shown in Table 4.

Tab. 4 The ADF unit root tests on residual sequence

\begin{tabular}{cccccccc}
\hline $\begin{array}{c}\text { Sequen } \\
\text { ce }\end{array}$ & $\begin{array}{c}\text { Level } \\
\text { Inspection } \\
\text { forms } \\
(c, t, n)\end{array}$ & ADF & $1 \%$ & $5 \%$ & $10 \%$ & Accompa \\
& & thresholds & $\begin{array}{c}\text { Conclusi } \\
\text { threshold } \\
\text { threshold } \\
\text { thied }\end{array}$ & $\begin{array}{c}\text { on } \\
\text { probabilit } \\
\text { th }\end{array}$ \\
\hline $\begin{array}{c}\text { Residua } \\
\text { ls }\end{array}$ & $(0,0,3)$ & -1.98142 & -2.692358 & -1.960171 & -1.60705 & 0.0479 & Smooth \\
\hline
\end{tabular}

From Table 4:Through the stationary test of residuals et, the ADF test statistic values of residuals are less than the critical value of under $10 \%$ significance level .Reject the null hypothesis of existence of unit root, that is considered the residual sequence is stationary sequence, this indicates that there is a correlation co-integration between the LNC and LNX. That is within the sample interval, there is a long-term stable equilibrium relationship between the total import and export volume and carbon emissions, the specific relationship is equation $\mathrm{LNC}=0.3603 \times \mathrm{LNX}+8.4717$, that foreign trade volume of China increased by $1 \%$, carbon emissions of China increased by $3 \%$ 0.360 , shows that foreign trade have a certain effect on our carbon emissions. 


\section{Error Correction}

Establish error correction model to analyze the dynamic relationship between carbon emissions and our foreign trade[5],calculated by eviews6.0 introduce a first-order differential after error correction

model: $\Delta \mathrm{LNC}_{t}=0.1293 \times \Delta \mathrm{LN} X_{t}+0.4525 \times \Delta \mathrm{LNC}_{t-1}+0.0318 \times \Delta \mathrm{LN} X_{t-1}-0.2905 e_{t-1}+0.0033$, while the correlation coefficient $R=0.8304$,statistics $F=8.9$ corresponding to $F$ statistics the probability value is $p=0.006$ less than significant level $\alpha=0.05$. DW $=1$.97. In the absence of the autocorrelation range, indicating that there are some changes in the relationship between short-term dynamics of foreign trade and carbon emissions.

The regression results indicate short-term changes in foreign trade of China growth in the presence of a positive impact on carbon emissions, current every $1 \%$ increase in foreign trade, current carbon emissions will increase by $0.1293 \%$,previous each $1 \%$ increase in foreign trade, current carbon emissions will increase by $0.0318 \%$,previous carbon emissions also exists a positive influence on current carbon emissions, previous carbon emissions on every $1 \%$ increase, current carbon emissions will increase by $0.4525 \%$.

\section{Conclusions and Suggestions}

\section{Conclusions}

To illustrate the relationship between the foreign trade import and export volume of China and carbon emissions of China, this paper analyzes the data of them from 1990 to 2012, drawn that between 1990-2012 our carbon emissions and foreign trade export volume to maintain a similar growth trend. Before 2002, carbon emissions and import and export volume of Chinese foreign trade are in a state of slow growth, then in a fast growth. Explains that for a long time, the foreign trade contributed to the rapid increase of unreasonable carbon emissions. There is a high correlation between long-term positive and significant relationship between import and export volume of the foreign trade carbon emissions. After co-integration explain the existence of a stable long-term equilibrium relationship between them, the trade has a positive role in promoting on carbon emissions. Its long-term elasticity coefficient is 0.3603 . By error correction can be seen there is also a short-term dynamic equilibrium relationship between the them. In the short term, the current foreign trade volume for each $1 \%$ increase in current carbon emissions will increase $0.1293 \%$, non-equilibrium error to lag a current ratio of $29.05 \%$ carbon emissions to make amendments, promotes foreign trade and carbon emissions to long-term equilibrium relationship. Thus, in the long term, the development of our foreign trade will continue to affect our country's environmental problems.

\section{Suggestions}

\section{Accelerate economic growth mode}

At present, China is still the extensive economic growth mode, such economic development is bound to create enormous pressure on our environment. So in the process of our economic development, we should fully recognize the importance of the economic development approach in dealing with our country's resources and environment and foreign trade. Therefore, to accelerate the pace of adjustment of the economic development mode, implement resource-saving and environment-friendly industrialization and urbanization strategy, optimize the industrial structure and energy consumption structure, so that our economy comes into the fast low-carbon 
development road, thus achieving a virtuous ecological cycle of the foreign trade[6].

\section{Reasonable planning industrial trade layout}

Foreign trade of China growth mainly depends on the product or resource-intensive manufacturing, its production and consumption process is relatively high carbon emissions, causes of structural environmental pollution. Therefore, the foreign trade layout should bet rational planned, accelerate the elimination of backward production capacity and polluting enterprises. China is very urgent need to conduct low-carbon energy technology innovation[7], focus on improving the production technology of high energy-consuming enterprises, increase the carbon products industry in the proportion of our foreign trade.

\section{Establish an early warning mechanism of carbon emissions in foreign trade}

Since our country does not have established an early warning mechanism of foreign trade environment, meanwhile, the development of international environmental law, our economic development and the production methods are also put forward higher requirements. In this context, establish of an early warning mechanism of foreign trade carbon emissions need to put on the agenda, establish of foreign trade and environmental pollution monitoring system information, select the appropriate warning evaluation, depending on the industry's carbon emissions, a modest portion of carbon tariffs charged. Force our foreign trade in good a atmosphere.

\section{Acknowledgement}

This research was financially supported by the National Science Foundation.

\section{References:}

[1] Peters G P, Andrew R M, Boden T, et al. The challenge to keep global warming below $2{ }^{\circ} \mathrm{C}[\mathrm{J}]$. Nature Climate Change, 2013,(3):4-6.

[2]Shouhong Xie,Xiyuan Xu,et al.An Empirical Study of Chinese carbon emissions and Economic Growth[ J]. Resource Development \& Market 2013, 29(1):28 —31,40.

[3] Guoquan Xu,Zuyuan Liu,et al.Decomposition of Carbon Emissions for China Model and Empirical Analysis: 1995-2004[J].China Population, Resources and Environment, 2006, 16(6): $158-161$.

[4] Jingshui Sun.Econometrics[M].Beijing: Tsinghua University Press,2009, 294-337.

[5] Tiemei Gao.Econometric analysis and modeling - EViews applications and examples[M].2nd edition. Tsinghua University Press, 2009.

[6] Guangyue Xu,Deyong Song.Chinese export trade and economic growth empirical study of the relationship between carbon emissions[J].International trade issues2010(1):74-79.

[7] Aiwen Zhao,Dong Li.An Empirical Analysis of carbon emissions between China and the relationship between economic growth decoupling[J]. Technical and economic, 2013, 32(1):106-111. 